\title{
Erratum to: The Ladder of Rationality
}

\section{John Broome: Rationality Through Reasoning Oxford, Wiley}

Blackwell, 2013, ISBN 978-1-4051-1710-4, 308 pages, £24.99/€31.30

\section{Julian Fink ${ }^{1}$}

Published online: 6 February 2016

(C) Springer Science+Business Media Dordrecht 2016

\section{Erratum to: Ethic Theory Moral Prac \\ DOI 10.1007/s10677-015-9642-0}

The published online paper contains an error. Three sentences need to be replaced. First, on page 5,

By contrast, rationality prohibits basing not-intending to $\mathrm{X}$ on not-believing that you ought to $\mathrm{X}$. needs to be replaced with

By contrast, rationality prohibits basing not-believing that you ought to $\mathrm{X}$ on not-intending to $\mathrm{X}$.

Second, on page 5, last paragraph,

Rationality prohibits your basing not-intending to X on not-believing that you ought to X (141, 187). You cannot rationally base lacking an intention to $X$ on not-believing that you ought to $X$. need to be replaced by the following two sentences

Rationality prohibits your basing not-believing that you ought to X on not-intending to X (141, 187). You cannot rationally base lacking a belief that you ought to $X$ on not-intending to $X$.

The online version of the original article can be found at http://dx.doi.org/10.1007/s10677-015-9642-0.

Julian Fink

julian.fink@philo.unibe.ch

1 Department of Philosophy, University of Bern, Länggassstrasse 49a, CH-3012 Bern, Switzerland 